\title{
The relationship between intimate partner violence and postpartum depression in Osogbo, Nigeria
}

\author{
Adejoke D. Abiodun' ${ }^{1}$, Boladale Mapayi ${ }^{2}$, Afolabi B. Abiodun ${ }^{3 *}$, \\ Julianah T. Mosanya ${ }^{1}$, Adeleye A. Adeomi ${ }^{4}$
}

\begin{abstract}
${ }^{1}$ Department of Psychiatry, Ladoke Akintola University of Technology Teaching Hospital, Osogbo Osun State, Nigeria ${ }^{2}$ Department of Psychiatry, Obafemi Awolowo University Teaching Hospital Complex Ile-Ife, Osun State Nigeria ${ }^{3}$ Department of Family Medicine, Subol Hospital Ltd, Idimu, Lagos, Nigeria

${ }^{4}$ Department of Community Medicine, Obafemi Awolowo University Teaching Hospital Complex Ile-Ife, Osun State Nigeria
\end{abstract}

Received: 12 August 2018

Accepted: 06 September 2018

\section{*Correspondence:}

Dr. Afolabi B.Abiodun,

E-mail: abiodunben@yahoo.com

Copyright: (C) the author(s), publisher and licensee Medip Academy. This is an open-access article distributed under the terms of the Creative Commons Attribution Non-Commercial License, which permits unrestricted non-commercial use, distribution, and reproduction in any medium, provided the original work is properly cited.

\begin{abstract}
Background: Postpartum depression is the most prevalent postpartum mental health problem. Risk factors for postpartum depression include psychosocial stressors. One of these psychosocial stressors could be intimate partner violence. Co-occurrence of intimate partner violence and postpartum depression is considered deadly co morbidity because it can increase the risk of homicide and suicide. The aim of this study was to determine the relationship between intimate partner violence and depression among postnatal women attending postnatal and infant welfare clinics of LAUTECH Teaching Hospital, Osogbo.

Methods: A descriptive cross-sectional study was conducted among 220 postpartum women who attended postnatal and infant welfare clinics of LAUTECH Teaching Hospital in Osogbo using Composite Abuse Scale (CAS), Edinburgh Postnatal Depression Scale (EPDS) and Socio-demographic questionnaire. Respondents that were found to be EPDS positive as well as $10 \%$ of EPDS negative respondents were further assessed with Mini International Neuropsychiatric Interview (MINI) (depression subscale) to diagnose depression.

Results: Respondents that experienced intimate partner violence were five times as likely to have postpartum depression compared to those that did not experience IPV. Logistic regression showed that intimate partner violence independently predicted postpartum depression in respondents (OR 4.799, CI 1.844-12.493).

Conclusions: Postpartum depression was significantly higher among women that experienced intimate partner violence. This observation has implications for mental health of women, therefore, any woman with suspected postpartum depression should be asked about IPV as this could be a pointer to IPV.
\end{abstract}

Keywords: Intimate partner violence, Nigeria, Osogbo, Postpartum depression, Relationship

\section{INTRODUCTION}

Intimate partner violence (IPV) is a public health issue in both developed and developing countries. ${ }^{1}$ It is defined as a pattern of assaultive and coercive behavior that may include inflicted physical injury, psychological abuse, sexual assault, progressive social isolation, deprivation, intimidation and threats by a current or former intimate partner. ${ }^{2,3}$

Globally, at least one in three women has experienced some form of gender-based violence during her 
lifetime., ${ }^{4,5}$ A World Health Organization(WHO) study showed that $31 \%$ of Nigerian women are physically abused by an intimate partner during their lifetime and that Nigeria is one of the nations where men see the ability to inflict physical punishment on their wives as a right. ${ }^{1}$ The prevalence in Nigeria varies from one region to the other with a range of $11-79 \% .^{2,6-10}$ Mapayi et al found a prevalence of $37 \%$ in a South West Nigerian sample of women of childbearing age in primary care settings. ${ }^{2}$ Though the prevalence of IPV remains high in less developed countries, data suggest that these figures may represent an underestimation considering that many women are unwilling to disclose and seek help because of fear of ostracization. ${ }^{1}$

The postpartum period may be a particularly vulnerable time for experiencing harms associated with intimate partner violence. ${ }^{4}$ A recent study carried out by Desmaris et al in 2014 found that women exposed to intimate partner violence during pregnancy reported rates of depression that were approximately twice the rates reported by mothers who did not experience intimate partner violence. ${ }^{4}$

Postpartum depression (PPD) is the most prevalent postpartum mental health problem. ${ }^{4}$ Postpartum depression is a clinically significant depressive episode that begins in the postpartum period. ${ }^{11}$ It is a disorder lasting more than two weeks and requires medical attention. $^{12}$ The Marce society, an international organization for the study of psychiatric illness related to childbearing, recognizes the period of vulnerability for postpartum depression as one year after delivery. ${ }^{13}$

During their reproductive years, women are at increased risk for emotional disorders. ${ }^{14}$ Commonly identified risk factors for postpartum depression are family history of depression, being a single mother, poor relationship with own mother, unwanted or ambivalence towards pregnancy, poor social support, severe maternal blues, previous postpartum psychosis and certain other significant psychosocial stressors like intimate partner violence. $^{12,15}$

In developing countries such as Nigeria postpartum depression has been found to be associated with low birth weight and poor infant growth. ${ }^{16}$ As a result, there is need for more knowledge about the role of IPV as a risk factor in postpartum depression. ${ }^{17}$

The postpartum period provides a good opportunity to screen for intimate partner violence against women and postpartum depression as many women would bring their children for immunization and women tend to trust and confide in health workers. ${ }^{18}$ Also, early screening is an important strategy for ensuring these health issues are detected and awareness is raised about their importance. ${ }^{18}$ Efforts to understand the pattern of help seeking by victims of IPV is of considerable importance in order to be able to design systems and responses that are capable of actively and appropriately meeting the needs of victims.

\section{Postpartum depression and intimate partner violence}

Intimate partner violence (IPV) and postpartum depression (PPD) are both extremely important public health concerns. ${ }^{19}$ Women from all racial, ethnic, cultural and socioeconomic backgrounds and of all ages are at risk for experiencing both PPD and IPV.

A positive link between depression and IPV has been established but the causation remains in question. ${ }^{20}$ The health belief model links IPV to PPD. The health belief model has four concepts which are perceived susceptibility, perceived severity, perceived benefit of action and perceived barriers to action. ${ }^{21}$ A person's belief about the severity of a condition determines her attitude as regards wanting to prevent its occurrence or seek help for it. It has been shown that partner abuse may contribute to depression and that when IPV is treated there is a reduction in the depressive symptoms. ${ }^{20,22}$ Ludemir et al found that over half of women in a Brazilian study who experienced physical, sexual or psychological violence from an intimate partner during pregnancy experienced elevated rates of PPD. ${ }^{23}$ Similar results were found in a study conducted in Hong Kong, in which exposure to psychological violence during pregnancy was associated with a greater risk of PPD. ${ }^{24}$

Research shows that IPV can strongly increase one's risk of experiencing depression. ${ }^{25}$ A study found that women who experienced IPV during pregnancy were 2.5 times more likely to report being depressed than those who did not. $^{25}$ In addition, another study reported that IPV is strongly associated with postpartum depression especially when other social stresses such as marital relations, work, poor finances, and housing difficulties are also present. ${ }^{26}$ Regardless of varying rates of IPV/PPD prevalence, the negative effects of IPV are well documented and include preterm labor, low birth weight, future child abuse, and femicide. ${ }^{27}$

Homicide (by a partner) accounts for 31 percent of all maternal injury deaths and is the second leading cause of traumatic death for pregnant and postpartum women in the United State. ${ }^{28}$

Long-term experiences of violence are extremely important to recognize, as having a history of trauma, violence, and abuse are risk factors for future serious physical and mental health issues for women. ${ }^{29}$ The individual experiences of IPV and PPD as traumatic experiences are not only exacerbated by previous histories of trauma, abuse and depression, but can further contribute to a woman's lifetime experience of trauma and mental health, placing her at greater risk throughout her lifetime. ${ }^{30}$ In addition, subtle forms of social and cultural victimization can be re-traumatizing. ${ }^{19}$ Screening for IPV and PPD is therefore very important. 
Few studies have assessed intimate partner violence and postpartum depression in Nigeria and the relationship has not been well explored in the catchment area of the present study. Previous studies focused mainly on the prevalence of IPV amongst women in various parts of Nigeria. Therefore, investigating the relationship between intimate partner violence and postpartum depression as an important area of research is essential because it will provide empirical evidence of the relationship, provide baseline data in our environment and provide the basis for the formulation of preventive strategies aimed at improving maternal and child health.

\section{METHODS}

The study was conducted at the infant welfare and postnatal clinics of Ladoke Akintola University of Technology (LAUTECH) Teaching Hospital (LTH) Osogbo, Osun State.

Women attending these clinics were consecutively selected and those who met the inclusion criteria and gave informed consent were recruited for the study until the sample size was achieved. A removable identification sticker was left on all patients' card until the completion of the study to avoid a repeat selection. The selfadministered questionnaires were filled by all mothers that met the inclusion criteria at the same time. For those who were not able to read in Yoruba or English, the research assistant helped to administer the questionnaire to them after obtaining informed consent. The research assistant collected the questionnaires, scored the Edinburgh Postnatal Depression Scale (EPDS) and sent those with a cut-off score of 10 or higher to the researcher to be interviewed with Mini International Neuropsychiatric Interview (M.I.N.I) Depression module by the researcher. The interview was conducted in a private office, the respondents were put at ease and rapport was established before administration of the instrument.

Data collection was done using the following instruments:

\section{Socio-demographic questionnaire}

The socio-demographic information of respondents, including age, residence, marital status, number of husband's wives, position among husband's wives, family settings, family size, sex of index child, sex of previous children, level of education of both participant and partner, employment status of respondent and partner's monthly income were enquired about.

\section{Questions on pregnancy related factors}

This aspect of the questionnaire enquired about support during pregnancy, mode of delivery, duration of delivery and no of weeks since delivery

\section{Questions on past history of exposure to violence}

This section of the questionnaire enquired about experience of physical violence from home of origin before the age of 18 years, witnessing physical abuse in home of origin before age of 18 years, experience of sexual abuse before 18 years and witnessing sexual abuse before 18 years.

\section{Questions on alcohol use}

This section of the questionnaire enquired about alcohol use of respondents and their partners' alcohol use

\section{Questions on help seeking behaviour}

This aspect of the questionnaire enquired about attitude of respondents to violence against women, attitude of respondents to help seeking, reason for seeking help or otherwise and from whom help is sought.

\section{Edinburgh Postpartum Depression Scale (EPDS)}

The Edinburgh Postpartum Depression Scale has been used as a screening tool for assessment of depression in a variety of clinical settings. ${ }^{11}$ It is a self-administered questionnaire which consists of 10 questions with four response categories scored from 0 to 3 , whereby the greatest values represent depressed moods. ${ }^{31}$ Mothers who obtained an EPDS total score of 10 or greater were labelled as having postpartum depression. ${ }^{32}$ The range of scores for EPDS is from 0 to 30 . Since its publication in the 1980s, it has been used in a growing number of studies across a variety of patient groups..$^{11,33,34}$ It has been validated in Nigeria. ${ }^{32,34}$ Sensitivity was $75 \%$ while specificity was 97\%.34 The reliability of the EPDS was 0.83 using Cronbach's alpha. ${ }^{34}$ EPDS is a valid screening test for detecting postpartum depression. ${ }^{32}$ A cut-off score of 10 or higher on EPDS was found to be the optimum for screening for depression..$^{32,34}$

\section{Composite Abuse Scale (CAS)}

It is a 30-item validated self-administered research instrument. ${ }^{35}$ It is based on a concept of intimate partner violence (IPV) that includes coercion and not simply violent acts arising out of conflict. ${ }^{35}$ It is recommended as an IPV research assessment tool by the National Centre for Injury Prevention and Control because it has demonstrated a high level of reliability and validity in self-reported prevalence of IPV., 2,36 The CAS measures four dimensions of abuse (1) physical abuse, (2) emotional abuse, (3) severe combined abuse and (4) harassment. There are physical, emotional, severe combined abuse and harassment have 7, 11, 8 and 4 items respectively. A preliminary cut-off score of 7 divides respondents into abused and non-abused. ${ }^{2}$ It has high internal consistency (Cronbach's alpha) of at least 0.90 for each subscale and an all item total score correlation of 0.6. ,35 $^{2,}$ was selected for its comprehensiveness and 
strong psychometric properties. It has been validated with a large sample of patients in primary care practice setting. ${ }^{35}$ The CAS has been used in Nigeria and showed face validity and good internal consistency with a Cronbach's alpha of $0.82 .^{2}$ A cut off score of 7 was adapted for this study in accordance with the findings of Hegarty et al. ${ }^{35}$ The range of scores for CAS is from 0 to $150 .^{36}$ The range of scores for each dimension is 0 to 40 , 0 to 55,0 to 35 and 0 to 20 for severe combined abuse, physical abuse, emotional abuse and harassment respectively. ${ }^{36}$ For the four subscales, the cut off score was $\geq 1, \geq 1, \geq 3$ and $\geq 2$ for severe combined abuse, physical abuse, emotional abuse and harassment respectively. ${ }^{36}$

\section{Mini International Neuropsychiatric Interview (M.I.N.I)}

\section{Depression module}

The M.I.N.I is a short structured diagnostic interview developed jointly by psychiatrists and clinicians in the United States and Europe in 1990 for DSM-IV and ICD10 psychiatric disorders. It has acceptably high validation and reliability scores when compared with other structured diagnostic interview schedule but can be administered in a much shorter period of time. The M.I.N.I is divided into modules identified by letters each corresponding into a diagnostic category.

At the beginning of each diagnostic module (except for psychotic disorders module) screening question(s) corresponding to the main criteria of the disorder are asked. At the end of each module, diagnostic box (es) permit the clinician to indicate whether diagnostic criteria are met.

Each module assesses for a diagnostic category. Major Depressive Episode module of MINI which is grouped as 'A module' has six sections A1 to A6. In this study questions A1 to A3 were used since the study assesses major depressive episode (current) and women with previous history of depression have been excluded from the study.

\section{Data Analysis}

At the end of data collection, the administered questionnaires were sorted out and coded serially. All data collected were analyzed using the Statistical Package for Social Sciences (SPSS) software (version 21).

Results were presented using frequency distribution tables and relevant statistics such as percentages, means and standard deviations.

Cross tabulations were done to compare the outcome variables for IPV and Postpartum Depression. Chi square statistic was used to evaluate the association between variables. Statistical significance was set at $\mathrm{P}<0.05$.

\section{RESULTS}

\section{Socio-demographic characteristics of the respondents}

Two hundred and twenty questionnaires were administered to the study group and all the questionnaires were completed, giving a response rate of $100 \%$.

Table 1: Socio-demographic characteristics of the respondents $(\mathrm{N}=\mathbf{2 2 0})$.

\begin{tabular}{|c|c|c|}
\hline & Frequency $(n=220)$ & $\%$ \\
\hline \multicolumn{3}{|l|}{ Age (years) } \\
\hline$\leq 20$ & 2 & 0.9 \\
\hline $20-29$ & 89 & 40.4 \\
\hline $30-39$ & 124 & 56.4 \\
\hline$\geq 40$ & 5 & 2.3 \\
\hline \multicolumn{3}{|l|}{ Mean age $30.12( \pm 4.76)$} \\
\hline \multicolumn{3}{|l|}{ Marital Status } \\
\hline Cohabiting & 25 & 11.4 \\
\hline Married & 195 & 88.6 \\
\hline \multicolumn{3}{|c|}{ Marriage/cohabitation pattern } \\
\hline Monogamous & 200 & 90.9 \\
\hline Polygamous & 20 & 9.1 \\
\hline \multicolumn{3}{|l|}{ Employed } \\
\hline Yes & 167 & 75.9 \\
\hline No & 53 & 24.1 \\
\hline \multicolumn{3}{|l|}{ Level of education } \\
\hline No formal education & 1 & 0.5 \\
\hline Primary & 11 & 5.0 \\
\hline Secondary & 57 & 25.9 \\
\hline Tertiary & 151 & 68.6 \\
\hline \multicolumn{3}{|l|}{ Tribe } \\
\hline Yoruba & 216 & 98.2 \\
\hline Igbo & 3 & 1.3 \\
\hline Others specified (Ishan) & 1 & 0.5 \\
\hline \multicolumn{3}{|l|}{ Place of residence } \\
\hline Urban & 214 & 97.3 \\
\hline Rural & 6 & 2.7 \\
\hline \multicolumn{3}{|l|}{ Religion } \\
\hline Christianity & 140 & 63.6 \\
\hline Islam & 79 & 35.9 \\
\hline Traditional & 1 & 0.5 \\
\hline \multicolumn{3}{|l|}{ Income pattern } \\
\hline Income $<18000$ & 117 & 53.2 \\
\hline Income $\geq 18000$ & 103 & 46.8 \\
\hline
\end{tabular}

The socio-demographic characteristics of the respondents are as shown in Table 1. The mean age of the respondents was $30.12( \pm 4.76)$ years. The respondents were mainly urban dwellers of Yoruba ethnic group and from monogamous family settings.

Women whose ages ranged between 30 and 39 years constituted more than half of the entire respondents. Christians constituted about two-third of the respondents. Majority of the women had education beyond the primary school level. Three-quarter of the respondents were employed. More than half of the respondents earn less 
than the current minimum wage of 18,000 Naira. (Table 1)

\section{Prevalence of intimate partner violence among the respondents}

The mean total score was 6.38 (11.96), median was 0.00 while the range was 63.00 . The mean score for group with score less than 7 was 0.63 (1.49), median was 0.00 while range was 6.00. Also, the mean score for group with score greater or equal to 7 was 22.07 (13.84), median was 19 while the range was 56.00. The prevalence of Intimate partner violence is as depicted in figure 1 below. A little above one fourth of the respondents (59) were exposed to IPV using CAS score of 7 and above. More than two third of the respondents (161) were not exposed to IPV (Figure 1).

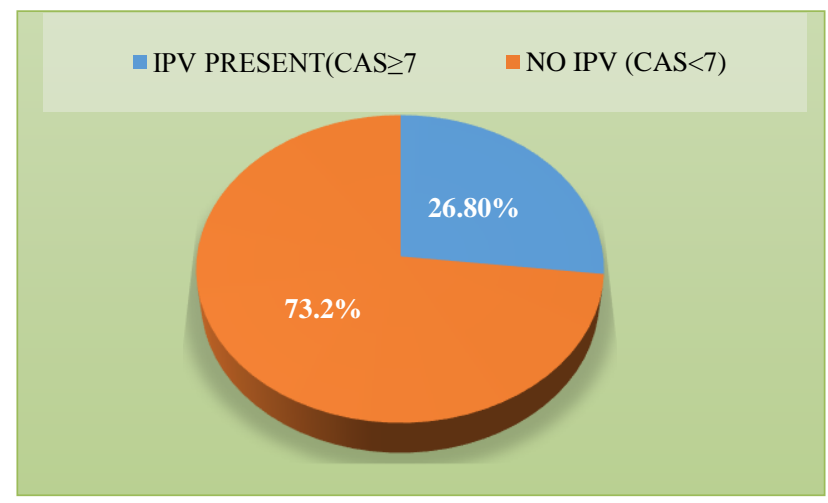

Figure 1: Prevalence of IPV

The mean EPDS score was 4.31 (5.34), median was 2.00 while the range was 20.00 . The mean value for respondents with score greater or equal to 10 was 13.89 (2.77), median was 14.00 while the range was 10 . Furthermore, the mean score for respondents with EPDS score less than 10 was 4.31 (5.34), median was 2.00 while range was 9.00. Screening for postpartum depression using EPDS is as highlighted in figure 2. Among the respondents, $39(17.7 \%)$ were considered depressed (EPDS score $\geq 10$ ) (Figure 2).

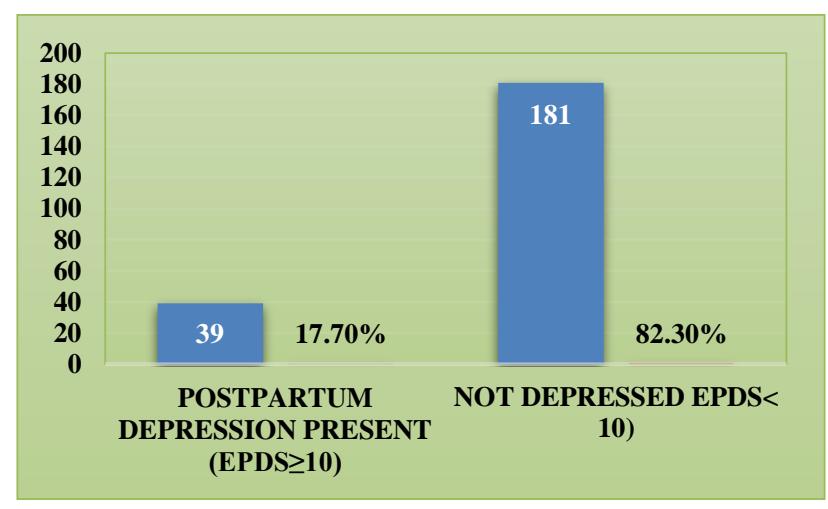

Figure 2: Screening for postpartum depression using EPDS

\section{Prevalence of Postpartum Depression Using MINI}

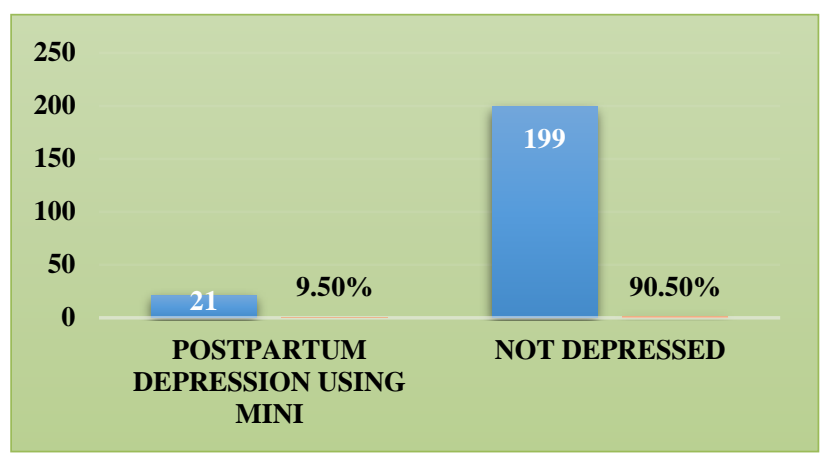

Figure 3: Prevalence of postpartum depression using MINI.

Figure 3 above depicts the prevalence of postpartum depression using MINI. Among the 57 respondents (39 EPDS positive and 18 EPDS negative) on whom MINI were administered, 21 respondents $(9.5 \%)$ met criteria for the diagnosis of major depressive episode. Sensitivity and specificity were $100 \%$ and $90.95 \%$ respectively while positive predictive and negative predictive values were $53.84 \%$ and $100 \%$ respectively. (Figure 3 )

\section{Association between postpartum depression and intimate partner violence}

The association between IPV and PPD is as shown in table 2 below. Postpartum depression in the respondents showed statistically significant association with being exposed to intimate partner violence. Twenty two percent of those who experienced intimate partner violence had postpartum depression as opposed to $5 \%$ who had no experience of intimate partner violence $(\chi 2=14.563, p$ $<0.001)$ (Table 2).

Table 2: Association between postpartum depression and experience of intimate partner violence.

\begin{tabular}{|llllll|}
\hline Variable & $\begin{array}{l}\text { Postpartum } \\
\text { depression } \\
\text { Yes n }\end{array}$ & $\begin{array}{l}\text { No n } \\
(\%)\end{array}$ & & df & p value \\
\hline IPV & $(\%)$ & & & \\
\hline Exposed & $13(22)$ & $46(78)$ & 14.563 & 1 & $<0.0001$ \\
\hline Not exposed & $8(5)$ & $153(95)$ & & & \\
\hline
\end{tabular}

Association between postpartum depression and intimate partner violence in respondents using logistic regression are as shown in Table 3 below. Intimate partner violence, categorized as 'exposed' and 'not exposed', was entered into a binary logistic regression model as an independent variable while postpartum depression (categorized into 'Depressed' and 'Not Depressed') was the outcome variable. Respondents who were exposed to IPV were 4.8 times as likely to have postpartum depression $(95 \%$ CI: 1.844 - 12.493) compared to respondents that were not exposed to IPV (Table 3 ). 
Table 3: Association between postpartum depression and intimate partner violence using logistic regression.

\begin{tabular}{|c|c|c|c|c|c|}
\hline \multirow[t]{2}{*}{ Variables } & \multirow[t]{2}{*}{ B } & \multirow[t]{2}{*}{ Odds ratio } & \multirow[t]{2}{*}{ p value } & \multicolumn{2}{|c|}{ 95\% CI for EXP (B) } \\
\hline & & & & Lower & Upper \\
\hline \multicolumn{6}{|c|}{ Support from husband } \\
\hline No (ref) & 1 & 1 & & & \\
\hline Yes & -0.984 & 0.374 & 0.066 & 0.131 & 1.068 \\
\hline \multicolumn{6}{|c|}{ Intimate partner violence } \\
\hline Not exposed (ref) & 1 & 1 & & & \\
\hline Exposed & 1.568 & 4.799 & 0.001 & 1.844 & 12.493 \\
\hline
\end{tabular}

\section{DISCUSSION}

This study examined the relationship between intimate partner violence and postpartum depression among women within 6 months postpartum period attending postnatal and infant welfare clinics of LAUTECH Teaching Hospital Osogbo. It also evaluated the prevalence of intimate partner violence as well as the prevalence of postpartum depression.

Majority (96.8\%) of the respondents were within the age 20 and 39 years, with a mean age of $30.12 \pm 4.76$ years. This is a young population and represents the reproductive and productive age group of the nation. Therefore, the need to focus on this age group for postpartum depression and intimate partner violence screening cannot be overemphasized in order to ensure a healthy and economically viable nation.

This study has shown that the prevalence of postpartum depression was significantly higher among respondents who experienced intimate partner violence (IPV) compared to those who did not in conformity with previous studies. ${ }^{4,19,23-25}$

In this study, there is a statistically significant association between postpartum depression and intimate partner violence. Thirteen (22\%) of those who experienced intimate partner violence had postpartum depression. Female survivors of IPV are at increased risk of suffering serious mental health problems that can continue years after the abuse has ended. This study suggests that the presence of IPV is an important risk indicator for postpartum depression because the prevalence of postpartum depression amongst respondents who had experienced violence was twice as much $(22 \%)$ as the prevalence in the sample $(9.5 \%)$. Furthermore, the odds of having postpartum depression was about five times as high in women who experienced IPV compared to those who did not experience IPV. This confirmed the findings from other settings of women experiencing current or past abuse by a partner. ${ }^{20,37,38}$ Although it is difficult to infer causation from this study, there is evidence that IPV may contribute to postpartum depression. In a prospective cohort study of Seattle women with history of IPV, when IPV was dealt with, depressive symptoms improved. ${ }^{22}$ In treating women who are depressed, doctors should be alert to the possibility of abuse. Ignoring the part partner abuse plays in postpartum depression reinforces the hidden nature of this issue for women. ${ }^{39}$

The association between depression and IPV in postpartum women was significant even after adjustment for variables associated with postpartum depression like age, support from partner and number of children. This confirmed the findings from other studies. ${ }^{37,38}$ Ludermir et al found that over half of women in a Brazilian study who experienced physical or sexual violence plus psychological violence from an intimate partner during pregnancy experienced elevated rates of PPD. ${ }^{23}$ Similar results were found in a study conducted in Hong Kong in which exposure to psychological violence during pregnancy was associated with a greater risk of PPD, although causation was not inferred. ${ }^{24}$

The association between IPV and postpartum depression in the study population was significant. Therefore, any woman with suspected postpartum depression should be asked about IPV, as this could be a critical factor in determining treatment options. Developing a treatment plan for depression that includes antidepressants or cognitive behaviour therapy or both without taking into account exposure to violence could reduce the effectiveness of these management strategy.

This study adds to the small but accumulating evidence from Nigeria that intimate partner violence is an important public health problem that is related to postpartum depression. To resolve it, many sectors need to work together at community, national and international levels. At each level, responses must include empowering women and girls, reaching out to men, providing for the needs of victims and increasing the penalties for abusers.

This study is one of the first in Nigeria to use standardised instruments in the measurement of IPV and its relationship with postpartum depression. It is therefore useful in providing part of a data base in our country that may be used for advocating policy reviews and development to protect the rights of women. It also paves the way for more research into this phenomenon in our society because it is an important public health issue. 
Early identification of IPV during pregnancy and postpartum depression after delivery is a gateway to detecting, preventing and ameliorating negative health conditions but both IPV and PPD remain issues marked by stigma, silence and dismissal.

\section{ACKNOWLEDGMENTS}

Authors would like to thank Prof. F.O Fatoye (late) for his supervision during study.

\section{Funding: No funding sources}

Conflict of interest: None declared

Ethical approval: The study was approved by the Ethics and Research Committee of LAUTECH Teaching Hospital Osogbo, Nigeria.

\section{REFERENCES}

1. Krug GE, Dahlberg LL, Mercy AJ, Zwi B. World report on violence and health. In: Lazano A, Lazano R, editors.; Geneva: World Health Organization; 2002. p. 90-6.

2. Mapayi B, Makanjuola ROA, Mosaku O, Adewuya $\mathrm{A}$, Afolabi O, Aloba $\mathrm{O}$, et al. Impact of intimate partner violence on anxiety and depression amongst women in Ile-ife, Nigeria. Arch Women's Mental Health. 2013;16(1):11-8.

3. Family Violence Prevention Fund. Preventing domestic violence: clinical guidelines on routine screening. San Francisco, CA: 1999.

4. Desmarais SL, Pritchard A, Lowder EM, Janssen PA. Intimate partner abuse before and during pregnancy as risk factors for postpartum mental health problems. BMC Preg Childbirth 2014;14(1):132.

5. Heise L, Ellsberg M, Gottemoller M. Ending Violence against women. Baltimore, MD: John Hopkins University school of Public Health, Center Communications Prog, 1999;27(4):1.

6. Fawole OI, Aderonmu AL, Fawole AO. Intimate partner abuse: Wife beating among civil servants in Ibadan, Nigeria. African J Reprod Health. 2005;9:5464.

7. Aimakhu CO, Olayemi O, Iwe CA, Oluyemi FA, Ojoko IE, Shoretire KA. Current causes and management of violence against women in Nigeria. $\mathbf{J}$ Obstet Gynaecol. 2004;24(1):58-63.

8. Ikeme AC, Ezegwui HU. Domestic violence against pregnant Nigerian women. Trop J Obstet Gynaecol. 2003;20(2):116-8.

9. Okemgbo $\mathrm{CN}$, Omideyi AK, Odimegwu CO. Prevalence, pattern and correlates of domestic violence in selected Igbo communities. African J Reproduct Health. 2002;6:101-14.

10. Onoh RO, Umeora OUJ, Ezeonu PO, Onyebuchi AK, Lawan OL, Agwu UM. Prevalence, pattern and consequences of intimate partner violence during pregnancy at Abakaliki Southeast Nigeria. Ann Med Health Sci Res. 2013;3(4):484-91.
11. Cox JL, Murray D, Chapman G. A controlled study of the onset, duration and prevalence of postnatal depression. British J Psychia. 1993;163(1):27-31.

12. Semple D, Smyth R, Burns J, Darjee R, Mcintosh A. Oxford Handbook of Psychiatry. Oxford University Press Inc New York; 2007. p. 756.

13. Parry BL, Haynes P. Mood disorders and the reproductive cycle. $\mathrm{J}$ Gender Speci Med. 2000;3(5):53-8.

14. Holden C. Sex and the suffering brain. Sci. 2005;308(5728):1574.

15. Munk-Olsen T, Laursen TM, Pedersen CB, Mars O, Mortensen PB. New parents and mental disorders: a population-based register study. J Am Med Assoc. 2006;296(21):2582-9.

16. Adewuya AO, Ola BO, Okeniyi AO. Impact of postnatal depression on infants' growth in Nigeria. J Affect Disord. 2008;108(1):191-3.

17. Oates M. Perinatal psychiatric disorders: a leading cause of maternal morbidity and mortality. Brit Med Bullet. 2003;67(1):219-29.

18. Shamu S, Abrahams N, Temmerman M, Musekiwa A, Zarowsky C. Shamu S, et al. A systematic review of African studies on intimate partner violence against women; Prevalence and risk factors. PLoS one 2011;6(3):e17591.

19. Hind AB, Ban al-sahab MS, May A, Hala T. Intimate Partner Violence as a Risk Factor for Postpartum Depression Among Canadian Women in the Maternity Experience Surveys. Ann Epidemiol. 2010;20(8):575-83.

20. Astbury J, Cabral M. Women's mental health; an evidence based review. World Health Organization; Geneva 2000.

21. Brown KM. Health Belief Model. James and Barlett Publishers; 2006.

22. Kernic MA, Holt VL, Stoner JA. Resolution of depression among victims of intimate partner: Is cessation of violence enough?. Violence and Victims. 2003;18(2):115-29.

23. Ludermir A, Lewis G, Valongueiro S, Araujo T, Araya R. Violence against women by their intimate partner during pregnancy and postnatal depression: a prospective cohort study. Lancet. 2010;376(9744):903-10.

24. Tiwari A, Chan K, Fong D, Leung W, Brownridge D. The impact of psychological abuse by an intimate partner on the mental health of pregnant women. Int J Obstet Gynecol. 2008;115(3):377-84.

25. Howard L, Trevillion K, Agnew-Davies R. Domestic violence and mental health. Int Review Psychia. 2010;22(10):525-34.

26. Beydoun H, Beydoun MA, Kaufman JS, Lo B, AB Z. Intimate partner violence against adult women and its association with major depressive disorder, depressive symptoms and postpartum depression: a systematic review and meta-analysis. Social Sci Medi. 2012;75(6):959-75.

27. Cerulli C, Talbot Nl, Tang W, Chaudron LH. Cooccuring intimate partner violence and mental health 
diagnoses in perinatal women. J Women's Health. 2011;20(12):1797-803.

28. Saltzman LE, Fanslow JL, McMahon PM, Shelley G, A. Intimate partner violence survellance:uniform definitions and recommended data elements, version1.0.Atlanta(GA): Centers for injury prevention and control. 2002.

29. Hathaway JF, Mucci LA, Silverman JG, Brooks DR, Mathews R, Pavlos CA. Health status and health care use of Massachusetts women reporting partner abuse. Am J Prevent Med. 2000;19(4):302-7.

30. Lancaster CA, Gold KJ, Flynn HA, Yoo H, Marcus SM, Davis MM. Risk factors for depressive symptoms during pregnancy: a systematic review. Am J Obstet Gynecol. 2010;202(1):5-14.

31. Cox JL, Holden JM, Sagovsky R. Detection of postnatal depression. Development of the 10-item Edinburgh Postnatal Depression Scale. British Journal of Psychiatry. 1987;150(6):782-6.

32. Ukwakwe R. Affective(depressive) morbidity in puerperal Nigerian women:validation of Edinburgh Postnatal Depression Scale. Acta Psychiatrica Scandinavica 2003;107(4):251-9.

33. Adewuya AO, Eegunranti AB, Lawal AM. Prevalence of postnatal depression in Western Nigerian women: a controlled study. International J Psychiat Clinical Pract. 2005;9(1):60-4.

34. Adewuya AO, Ola B, Dada AO, Fatoso O. Validation of the Edinburgh Postnatal Depression
Scale as a screening tool for depression in late pregnancy among Nigerian women. J Psychosoma Obstet Gynaecol. 2006;27(4):267-72.

35. Hegarty K, Bush R, Sheehan M. The Composite Abuse Scale: further development and assessment of reliability and validity of a multidimensional partner abuse measure in clinical settings. Violence and Victims. 2005;20(5):529-47.

36. Thompson MP, Basile KC, Hertz MF, Sitterle D. Measuring intimate partner violence victimization and perpetration: a compendium of assessment tools. National centre for Injury Prevention and Control, Atlanta. 2006.

37. Campbell J. Health consequences of intimate partner violence. Lancet. 2002;359(9314):1331-6.

38. Golding J. Intimate partner violence as a risk factor for mental disorders: a meta-analysis. Journal of Family Violence. 1999;14(2):99-132s.

39. Jewkes R. Intimate partner violence: causes and prevention. Lancet. 2002;359(9315):1423-9.

Cite this article as: Abiodun $\mathrm{AD}$, Mapayi $\mathrm{B}$, Abiodun AB, Mosanya JT, Adeomi AA. The relationship between intimate partner violence and postpartum depression in Osogbo, Nigeria. Int J Reprod Contracept Obstet Gynecol 2018;7:3911-8. 